\title{
Technical analysis of water absorption rate of ceramic tiles
}

\author{
Tan Yibing ${ }^{1}$ \\ 1 (Quality and Technical Supervision and Inspection Center of Xuchang (National Quality Supervision and Inspection Center for Ceramic \\ Products of China (Henan)),Xuchang, Henan China
}

\begin{abstract}
Water absorption is an important physical performance index to measure the quality of architectural ceramics products. The difference of water absorption test results between different laboratories is large, which cannot truly reflect the quality status of products, restricting the quality improvement of ceramic products and restricting the development of enterprises.This paper mainly analyzes the testing technology of water absorption of ceramic tile, and finds that the technical level of testing personnel, test water and vacuum system of equipment are the main factors affecting the results of water absorption test, and puts forward relevant Suggestions, which provides a strong basis for improving the testing technology of ceramic tile in the laboratory.
\end{abstract}

\section{Introduction}

In the decoration and maintenance, ceramic tiles are a very important material. The quality of ceramic tiles is closely related to house decoration and affects people's quality of life. Ceramic water absorption is an important physical performance index to measure the quality of ceramic products. In ceramic production, water absorption is usually used to reflect the sintering degree of ceramic products and indirectly indicate the size of apparent porosity. Therefore, the water absorption rate is extremely important and can not be ignored in the research and production practice of ceramic products. Therefore, the detection methods and results must be very rigorous and scientific.

The current detection method of ceramic tile water absorption is mainly based on GB/T 3810.3-2016 "Ceramic tile test method Part 3: Determination of water absorption, apparent porosity, apparent relative density and bulk density" [3]. At present, major domestic testing institutions, laboratories in the building materials field and related companies mainly use vacuum method as the main detection method of water absorption, and analyze the detection process of vacuum method, even if the same ceramic tile is tested, the water absorption rate between different laboratories is tested The results are quite different and cannot truly reflect the product quality status, which seriously restricts the improvement of enterprise product quality and restricts enterprise development.

\section{Influencing factors}

\subsection{Impact of personnel operation}

GB/T 3810.3-2016 "Ceramic Tile Test Method Part 3:
Determination of Water Absorption, Apparent Porosity, Apparent Relative Density and Bulk Density" requires one piece of ceramic tile taken out after being soaked in a vacuum container for 15 minutes in the vacuum method After the soaked suede is wringed dry by hand, the surface of each brick is gently wiped dry in turn. For the uneven surface, the suede should be used to wipe off the surface moisture briskly, and then immediately weigh and record. Analyzing the data of the unsatisfactory laboratory for the water absorption ability verification of ceramic tiles in 2019 and combining the situation to understand it shows that the inspectors do not have sufficient professional knowledge and have not fully grasped the test method in the water absorption rate detection process. The deviation of test results caused by human operation mainly includes the following aspects:

1. The material used to wipe the ceramic tiles does not use suede as required by the standard, but uses ordinary rags or cotton cloths, which leads to deviations in the test results;

2. Because chamois leather has a certain degree of water absorption, when using chamois leather, the wiping time is too long, and the moisture on the surface of the sample is wiped excessively, resulting in low water absorption test results;

3. The operation time of wringing the chamois is too long, or the chamois is not used for a long time after wringing, so that the chamois is too dry. When wiping the ceramic tiles, excessive moisture on the surface of the bricks will be taken away, resulting in low wet weight of the ceramic tiles, resulting in test results Too small

4. When the water absorption rate of ceramic tiles is tested continuously, the wringed chamois leather is used for a long time, which makes the water absorption state of the chamois inconsistent. When the ceramic tiles are 
wiped, the degree of wiping in each test is not uniform, which leads to deviations in the test results.

5. The ceramic tiles taken out from the vacuum device (system) have been placed in the air for too long, causing excessive evaporation of water on the surface of the tiles (especially in summer), resulting in low wet weight of the ceramic tiles, resulting in small test results.

Table 1 The influence of storage time on the wet weight of ceramic tiles

\begin{tabular}{|l|l|c|c|c|c|}
\hline \multicolumn{2}{|c|}{ Set time /min } & 0 & 0.5 & 1 & 2 \\
\hline \multirow{3}{*}{$\begin{array}{l}\text { Wet } \\
\text { weight /g }\end{array}$} & sample 1 & 180.92 & 180.76 & 180.47 & 180.22 \\
\cline { 2 - 6 } & sample 2 & 196.45 & 196.24 & 195.96 & 195.55 \\
\cline { 2 - 6 } & sample 3 & 230.69 & 230.55 & 230.41 & 230.25 \\
\hline
\end{tabular}

\subsection{Impact of testing equipment}

The equipment used in the ceramic tile water absorption test mainly includes a ceramic tile water absorption vacuum device (system), a drying oven and a dryer, and an electronic balance.

\subsubsection{Vacuum device}

At present, the commonly used ceramic tile water absorption vacuum device (system) in the laboratory is mainly composed of a vacuum container, a vacuum system, a water supply and drainage system, a vacuum degree automatic control system, a time control system and a box. The precision of the water absorption vacuum device (system) and the traceability of the technical parameters directly affect the accuracy and accuracy of the test data. However, there is currently no overall verification procedure or system for the ceramic tile water absorption vacuum device (system). The calibration specification basically adopts the separate calibration/verification of the pressure parameters and time parameters of the vacuum device (system), and lacks the overall verification of the system's sealing, water filling and control system. The deviation of measurement results and data may be caused by the following situations:

1. Most laboratories only calibrate or verify pressure parameters, but do not measure time parameters. The time measurement results are inaccurate, resulting in pressure holding time and soaking time that do not meet the requirements of the test method, and the holding time and soaking time are too low. Cause the water absorption test result to be too small;

2. After the pressure parameter calibration/verification, there is no or failure to correctly confirm whether the measurement result meets the specified requirements, resulting in the vacuum degree not meeting the standard or specification requirements, the vacuum degree is low, and the water absorption test result is too small;
Table 2 Influence of vacuum degree on wet weight

\begin{tabular}{|c|l|c|c|}
\hline \multicolumn{2}{|c|}{ Vacuum /KPa } & 10 & 8 \\
\hline \multirow{3}{*}{ Wet weight /g } & sample 4 & 188.42 & 187.87 \\
\cline { 2 - 4 } & sample 5 & 198.86 & 198.03 \\
\cline { 2 - 4 } & sample 6 & 195.54 & 194.61 \\
\hline
\end{tabular}

3. The sealing ring of the main material of the sealing system has been aging for a long time, and the sealing is not tight enough, which causes the vacuum to be unable to maintain a constant pressure during the testing process, resulting in a small water absorption test result;

4. There is a problem in the water adding system, which makes the amount of water added insufficient or unstable, resulting in insufficient deionized water or distilled water to cover the brick body, or failing to meet the standard requirement of $5 \mathrm{~cm}$ above the top surface of the brick, making the brick incomplete or impossible Soaked in water well, the water absorption saturation of the brick is not enough, resulting in a small water absorption test result;

5. The water addition system with water circulation function uses deionized water or distilled water repeatedly for detection, resulting in too turbid water or impurities, which will also affect the water saturation of the brick, resulting in a small test result.

Table 3 Influence of test water on wet weight

\begin{tabular}{|c|c|c|c|c|c|}
\hline \multicolumn{2}{|c|}{ Test water } & $\begin{array}{c}\text { Distilled } \\
\text { water } \\
\text { (Sufficie } \\
\text { nt water) }\end{array}$ & $\begin{array}{l}\text { Distilled } \\
\text { water } \\
\text { (Just } \\
\text { submerge } \\
\text { d) }\end{array}$ & $\begin{array}{c}\text { Distilled } \\
\text { water } \\
\text { (Repeated } \\
\text { use) }\end{array}$ & $\begin{array}{c}\text { Tap } \\
\text { water }\end{array}$ \\
\hline \multirow{3}{*}{$\begin{array}{l}\text { Wet } \\
\text { weigh } \\
\text { t/g }\end{array}$} & sample 7 & 185.75 & 185.05 & 185.87 & 185.96 \\
\hline & sample 8 & 197.43 & 196.34 & 197.66 & 197.64 \\
\hline & sample 9 & 202.82 & 202.01 & 202.90 & 202.93 \\
\hline
\end{tabular}

\subsubsection{Electronic balance}

Electronic balances are mainly used to weigh the dry and wet weight of ceramic tiles.

1. Since the electronic balance is a high-precision measuring instrument, it has very high requirements on the working environment. When the electronic balance is placed on a channel with direct air circulation, it may cause unstable detection data. Vibration in the surrounding environment may also affect the detection data.

2. The instrument is not calibrated due to long use time, position movement, environmental changes, etc., the accuracy of the weighing data cannot be measured, and the 
data reliability is low.

\subsubsection{Drying box}

The drying box is used for the drying of ceramic tiles. When there is a correction value for the temperature parameter calibration/verification result in the drying oven, the setting temperature of the drying oven is not corrected, or the temperature uniformity and fluctuation of each part in the oven are large. When the temperature is lower than $110 \pm 5^{\circ} \mathrm{C}$, the brick When drying, the moisture in the bricks is not completely removed, and the drying is insufficient, which causes the dry weight of the bricks to be too large, resulting in a small water absorption test result.

\subsubsection{Dryer}

The dryer is used for short-term storage of ceramic tiles that have been dried to a constant weight and cooled to room temperature. When the silica gel (usually used desiccant agent) in the desiccator changes color and fails to be dried and recovered in time, or the lid of the desiccator is not tightly sealed, it can cause the ceramic tiles to absorb moisture in the air again, causing the dry weight of the tiles to be too large. As a result, the water absorption test result is too small.

\section{Conclusions and recommendations}

This article systematically analyzes the water absorption rate detection process of ceramic tiles from the aspects of inspectors and inspection equipment. The main factors that affect the water absorption rate test results of ceramic tiles are the technical level of the inspectors, the test water and the equipment vacuum system. It is recommended that major inspection agencies, Building materials laboratories and related companies actively participate in standard training and technical exchanges to promote technical capabilities; actively participate in inter-laboratory comparisons, proficiency verification, etc. to improve the technical level of laboratories in the field of ceramic tile water absorption testing. Provide strong data support to improve the quality of enterprises and promote the highquality development of the industry.

\section{References}

1. Zhou Enhu, Li Ziyun, Kang Jiarui. Analysis and discussion on the quality inspection plan of ceramic tiles[J].Science and Technology Communication, 2011(14):172+159.

2. National Standard of the People's Republic of China GB/T 4100 - 2015, ceramic tiles [S].

3. National Standard of the People's Republic of China GB/T 3810.3-2016, Ceramic Tile Test Method Part 3: Determination of Water Absorption, Apparent Porosity, Apparent Relative Density and Bulk Density [S]. 